\title{
La espacialidad neoliberal de la producción de vivienda social en las áreas metropolitanas de Valparaíso y Santiago (1990-2014): ¿hacia la construcción idelógica de un rostro humano?*
}

The neoliberal spatiality of social housing production in the
metropolitan areas of Valparaíso and Santiago (1990-2014):
for the ideological construction of a human face?

Rodrigo Hidalgo Dattwyler Voltaire Christian Alvarado Peterson

Daniel Santana Rivas

\begin{abstract}
Resumen
Más allá de la doctrina, el neoliberalismo se muestra como una ideología de producción espacial que ha comenzado a secuestrar el significado de reivindicaciones sociales, como el derecho a la ciudad y justicia espacial, convirtiéndolas en un "rostro humano" legitimador de la producción inmobiliaria, en el ámbito de acumulación capitalista. Este trabajo pretende indagar en los discursos oficiales involucrados en la generación de esta faceta, observando sus resultados en políticas de vivienda social tanto en Santiago como en Valparaíso, dentro del periodo señalado. Hacia el final se atienden cuestionamientos a este tipo de producción espacial, enfatizando en la hegemonía neoliberal y su rol en la gestión de un nuevo Estado neoliberal en Chile.
\end{abstract}

Palabras clave: ideología; vivienda social; neoliberalismo; utopías socio-espaciales.

\begin{abstract}
Beyond the doctrine, neoliberalism is shown as an ideology of spatial production that has begun to take over the meaning of social demands, such as the right to the city and spatial justice, converting these demands into a "human face" that legitimizes real estate production in the scope of capitalist accumulation. This paper aims to investigate official discourses involved in the generation of this facet, observing their results in social housing policies in Santiago and Valparaíso within the indicated period. Finally, this type of spatial production is questioned, emphasizing neoliberal hegemony and its role in the management of a new neoliberal State in Chile.
\end{abstract}

Keywords: ideology, social housing, neoliberalism, socio-spatial utopias. 
La crisis sistémica que ha vivido la economía global en las últimas décadas, ha implicado un nuevo esfuerzo por reestructurar la hegemonía neoliberal. Los movimientos sociales alternativos, con sus reivindicaciones en torno al derecho a la ciudad, han fallado una vez más en el juego de saltar escalas y en producir utopías socio-espaciales que sean efectivas alternativas al neoliberalismo, posibilitando así que éste absorba sus reivindicaciones para convertirlas en mecanismos dinamizantes, al servicio de flujos y fricciones (Herod, 1997).

El neoliberalismo ha buscado reestructurarse mediante la construcción de un rostro humano que, además de ser una medida para sostenerse a sí mismo como hegemonía ideológica, también resulta favorable para reproducir las relaciones sociales de producción capitalistas. Esta afirmación, sin embargo, debe ser examinada en detalle. El rostro humano impreso sobre el modo de acumulación de capital, no ha sido precisamente una invención de operadores financieros reunidos en las convenciones globales de magnates; por el contrario, representa una tendencia al ajuste que el Estado neoliberal aplica sobre las políticas que se dirigen a los pilares básicos de la reproducción social: educación, salud y vivienda. Las tres son áreas estratégicas sobre las que el Banco Mundial (2015) o el Banco Interamericano de Desarrollo (Blanco et al., 2014) intervienen periódicamente con sendos documentos, cuya pretensión central está en consolidar líneas de acción conjuntas dentro de un contexto regional. Para ello, las crisis económicas que han azotado tanto a España (Coq-Huelva, 2013) como a los Estados
Unidos (Crump et al., 2008; Niedt y Martin, 2013), han servido como un propedéutico en la gestión de las políticas bancarias y de responsabilidad fiscal.

Pero ¿a qué se refiere este rostro humano? Los estudios acerca del neoliberalismo y su relación con la producción de espacio, contienen una serie de elementos comunes, donde destacan su veloz e irreversible instalación y la importancia del control social como parte de los dispositivos de estabilidad del modelo (Foucault, 2007; Oxhorn, 1999); u otras referidas en los últimos treinta años por distintas corrientes de la geografía y las ciencias sociales a nivel latinoamericano (Borón et al., 2004). Con todo, esta humanización del modelo neoliberal, se instala en las formas que el Estado administra para la focalización de recursos, por una parte; pero que también organiza en la puesta marcha de las políticas residenciales sobre la propiedad, particularmente de la vivienda social. Por ello, la espacialidad de estas transformaciones ha sido relativizada, aun cuando es un proceso inherente $y$, por lo tanto, lógico dentro de la estructuración económica de las sociedades contemporáneas $y$, muy especialmente, en el caso chileno. Las imágenes de este rostro humano, así como algunas de sus facetas o principales características, están presentes de forma temprana en el trabajo de David Hojman (1995), que ha tenido otros impactos significativos a nivel nacional, sobre todo en lecturas críticas o benévolas con las formas que el modelo neoliberal ha asumido en las últimas décadas (Atria, 2013; Hidalgo et al., 2016a).

El propósito de este trabajo es caracterizar elementos de base teórica sobre 
aquellos componentes que dan estructura al rostro humano del neoliberalismo en Chile, cuya principal faceta de materialización y acción se localiza en el espacio social, principalmente el urbano; ello a partir de una revisión crítica a los documentos orientadores en la producción urbana, como práctica espacial desde el Estado, operada a través del Ministerio de Vivienda y Urbanismo chileno, entre los años 1990 y 2015. Por ello, se cotejan las principales ideas contenidas en las citadas fuentes y su relación con la construcción del relato ideológico del modelo neoliberal, a partir de evidencias normativas y de gestión territorial. Así, se establecen algunas directrices en la progresiva indagación sobre las economías que delimitan, modelan y articulan las relaciones socioespaciales en Chile, contexto territorial considerado con alevosa recurrencia como el Santo Grial de las economías sociales de mercado y, por sobre todo, como el alumno más aventajado en la instalación y perfeccionamiento del neoliberalismo.

\section{Cuando el "derecho a la ciudad" se convierten en una faceta del rostro humano del neoliberalismo}

Cuando Henri Lefebvre ([1973] 2014) señalaba que la producción implicaba no sólo la generación material de mercancías, sino de sentidos y significados; tenía en mente también que la producción del espacio se orienta a producir ideología (Hidalgo et al., 2016a). En ese sentido, Erik Swyngedouw, en un análisis sobre la elaboración de ideologías asociadas a la producción de naturaleza (2011), señala que una de las funciones de la ideología, es la de vaciar los contenidos sociales que se asocian a cierta categoría y reemplazarlos por otros que son útiles para ciertos fines políticos y económicos; de esa manera la sostenibilidad podría ser considerada como una ideología que intenta solucionar la degradación ecosistémica propia del desarrollo capitalista, a partir de mecanismos capitalistas como el pago por servicios ambientales, la venta de bonos de carbono y demás; vaciándose el contenido de la categoría naturaleza y dotándola de un nuevo sentido expresado como un "servicio" ambiental o ecosistémico (Swyngedouw, 2011). ¿Podría operar ese mecanismo de inversión ideológica respecto a las reivindicaciones del derecho a la ciudad? Carlos (2015) sostiene que, en efecto, esa categoría ha sido expropiada de quienes originalmente lucharon por ella, para ser transformada en una ideología con un alcance reformista. Se podría sostener entonces, que el neoliberalismo además de haber asumido un rostro verde, también busca un rostro humano y urbano, lo que implica vaciar de contenido tanto la noción de "derecho" como la de "ciudad" y darle nuevos sentidos. Desde luego, estos últimos dependen del contexto socio-espacial en el cual está inmerso el Estado, por lo que no resultarán, necesariamente, los mismos elementos significantes asignados para Chile (Zunino e Hidalgo, 2009), a los que se endilgan en los Estados Unidos o en el Reino Unido (Pierson, 1995).

En el caso chileno, las tensiones sociales y geográficas ocasionadas por la espacialidad neoliberal de la producción de vivienda implicaron, hasta mediados de la primera 
década de los dos mil, la construcción ideológica de nuevos contenidos tanto de la noción del derecho como de la ciudad, imbricados en las sucesivas políticas de vivienda social y de reformas urbanas (Rodriguez y Sugranyes, 2004; Posner, 2012). La hipótesis que aquí se defiende es que la ciudad se ha cargado con un nuevo significado: un contenedor apolítico de mixtura social; mientras que el derecho a la misma se asume como la facilidad del usuario - no del ciudadano precisamente - al acceso a servicios de transporte, educación y salud (Salazar et al., 2014b).

La ciudad sería entonces un espacio de mixtura social, entre clases medias y bajas la alta no aparece en el discurso, y la baja no es la que accede a la vivienda social sino la que reside en el centro en condiciones de precariedad - mientras que la noción de derecho a la ciudad se restringe a la facilidad de acceso a equipamientos que se mide, por la tecnocracia estatal, en distancias euclidianas (Sabatini y Brain, 2008). Ese nuevo sentido podría considerarse una forma no sólo de ganar un consenso político y atenuar el conflicto social potencial que genera la constitución de guetos inmensos en las periferias urbanas, sino una forma de abrir el lucrativo "mercado" de la vivienda social a las clases medias emergentes (Hidalgo et al., 2016b). Así el rostro humano y urbano del neoliberalismo chileno, estaría conduciendo a dos procesos: una "medianización con rasgos gentrificadores en el área central de la aglomeración de Santiago y Valparaíso" (Hidalgo y Borsdorf, 2005); y a la constitución de nuevas centralidades urbanas pero periféricas, configurando la localización y asiento de los proyectos de vivienda social para los pobres.
Sobre esto último, se concentra la atención de distintos trabajos, los cuales develan algunas de las "rugosidades espaciales" presentes en las soluciones habitacionales generadas durante las últimas décadas. En ellas, la lectura sobre el modelo neoliberal ha sido instalada desde una crítica a sus resultados, que pueden adicionarse a los ya citados respecto de distancias y servicios. Las lecturas sobre la gentrificación y las comunidades cerradas en las áreas periféricas metropolitanas del Gran Santiago (Sabatini y Salcedo, 2007); así como también la aplicación de modelos para el análisis de las fragmentaciones residenciales (Baehr y Meyer-Kriesten, 2007), han aportado interesantes insumos en la discusión, elevando la prioridad de intervenir sobre la conformación de un discurso-relato de Estado. Esto no deja de ser interesante, toda vez que el grueso de las discusiones sobre el modelo, se producen desde la crítica a la desregulación o el rol de los agentes privados.

\section{La construcción del rostro humano en el neoliberalismo chileno}

La idea acerca de una economía social de mercado no es para nada nueva y menos en Chile. La investigadora Pilar Vergara (1984) describe tempranamente la revolucionaria instalación del modelo, como una apuesta por convertir los bienes sociales en sustancias tasables y transables, en función de las necesidades de mercado. Entre otros elementos, se apoya en fuentes inmediatas a 
los acontecimientos, permitiéndole establecer tres aristas esenciales en el discurso de los instaladores del modelo neoliberal en plena dictadura militar - 1973 a 1990 -, para comprender la mecánica del nuevo orden económico, las que han servido de guía para estudios consecutivos (Pozo y Vergara, 1990; Gárate, 2012):

a) el colapso del Estado de bienestar que, debido su gran escala y modelo de empleabilidad, pensiones y definición estratégica en el marco de políticas públicas, había impedido el emprendimiento, desarrollo y progreso del país durante el siglo XX;

b) el Estado, como asignador de recursos y actor principal en el mercado, demostraba ser un ineficaz administrador de las áreas sensibles para la población como salud, vivienda y educación; por lo tanto, debía reducir sus acciones hacia el aseguramiento de estas demandas para quienes quedaran fuera del nuevo sistema privado;

c) este nuevo Estado subsidiario sería el garante institucional en la estabilidad de las reglas del juego de las inversiones y emprendimiento económico, y actuaría como sostén ante los moral hazards inevitables en el progreso de las iniciativas privadas. ${ }^{1}$

Estas aristas son pequeños testigos del efecto revolucionario que la acción cívicomilitar tuvo sobre lo público. El golpe de Estado de 1973 en Chile es, de todas maneras, un evento refundacional en base a la violencia política, control social y transformación económica (Moulian, 2002; Valdivia et al., 2006-2008) pero también constituye un nuevo pivote en la producción de espacio.
El sostenido proceso de perfeccionamiento en la distribución de los subsidios para la vivienda social, supone la activa presencia del Estado como agente esencial en la producción de espacio residencial e inmobiliario. Si bien es cierto no ejerce un rol como constructor, sí dinamiza activamente al mercado y las transacciones entre agentes privados y sociales para garantizar el acceso, por la vía de aportes hacia la demanda (Tapia, 2014; Hidalgo et al., 2016a). Esta sinergia va de la mano con la intervención focalizada sobre la vivienda social, como principal fuente en la generación de una propiedad residencial expandida. Pero también emerge una intención fuerte sobre la radicación y normalización de tomas de terreno y campamentos; así como también en el saneamiento de títulos de dominio, acciones articuladas por distintas agencias públicas desde 1980 en adelante (Hidalgo, 2005). La finalidad en destacar estos elementos consiste en que no sólo casa nueva responde a esta idea de enfoque subsidiario desde el Estado, sino que también actúa de forma reiterada sobre sus anteriores políticas (Calvacanti y Cruz, 2014; Borsdorf e Hidalgo, 2008).

Son estas acciones políticas las que, precisamente, materializan el rostro humano del neoliberalismo y sus evidencias en la producción de espacio. En efecto, el neoliberalismo manifiesta una faceta espacial, debido a que la forma de reproducción del capital se sostiene en la renta futura sobre la propiedad residencial y, también, en base al flujo de deuda hipotecaria que la banca comercial capitaliza en los mercados 
internacionales de bonos a largo plazo (Stiglitz, 2014; Krugman, 1992).

\section{La continuidad del modelo: fortalecimiento neoliberal estructural}

Ahora bien ¿cómo intervienen estos elementos en la producción de vivienda social? Los Estados contemporáneos, sobre la base de fundamentar o entregar un acervo reflexivo para las políticas públicas, mandatan estudios e informes de carácter técnico para intervenir en áreas deficitarias en cuanto a servicios mínimos sociales, siendo la vivienda uno de ellos. ${ }^{2}$ El caso chileno es un ejemplo de ello: considerando que, para finales de la década de 1970 comienza una transformación del espacio urbano, en razón a la apertura del mercado de suelos, no fueron pocos los documentos elaborados para sustentar "técnicamente" la producción de propiedad residencial focalizada para los estratos sociales de menores ingresos quienes además, no seducían en ese entonces a la banca comercial en el otorgamiento hipotecas.

Siguiendo lo anterior, proponer que el Estado neoliberal pretenda modelar un rostro humano para la economía social de mercado no es, en absoluto, un acto de ingenuidad. La inacabada gestión de suelos en favor de la cobertura para este tipo de residencias, ha sido ajustada y perfeccionada en los últimos decenios, en pos de consolidar operaciones habitacionales. Si bien a inicios de la década de 1990, la inclusión de nuevos subsidios para viviendas de carácter social tuvo fines expansivos, esto no evitó que el déficit presente en ellas se redujera. El Cuadro 1 expresa una conducta expansiva de los gobiernos chilenos desde el año señalada en adelante, donde resalta la iniciativa durante las dos primeras presidencias; para seguir en la inauguración del nuevo siglo con una contracción sobre estas políticas (ver Cuadro 1).

\section{Cuadro 1 - Cantidad de instrumentos de subsidios habitacionales entregados por mandato presidencial (1992-2015)}

\begin{tabular}{|l|c|c|}
\hline \multicolumn{1}{|c|}{ Presidentes de la República } & Periodo de mandato & Instrumentos aprobados \\
\hline Patricio Aylwin Azócar & $1990-1994$ & 8 \\
Eduardo Frei Ruiz-Tagle & $1994-2000$ & 5 \\
Ricardo Lagos Escobar & $2000-2006$ & 4 \\
Michelle Bachelet Jeria & $2006-2010$ & 3 \\
Sebastián Piñera Echenique & $2010-2014$ & 1 \\
Michelle Bachelet Jeria & 2014 -actualidad & 3 \\
\hline
\end{tabular}

Fuente: Elaboración propia en base a datos proporcionados por Minvu (2015). 
En todo caso, no representan estos guarismos, la detención de Estado en la gestión subsidiaria-residencial; muy por el contrario, inaugura una estructura fiscal focalizada en la óptima cobertura de estos aportes. El siguiente cuadro exhibe algunos de los principales aportes fiscales para viviendas nuevas, subsidios habitacionales para nuevas residencias, las cuales pueden ser adquiridas de forma individual o colectiva (ver Cuadro 2).

Claro está, la acción subsidiaria tiene una materialización espacial relevante. La temida y anunciada escasez de suelo en las zonas centrales del país (Hidalgo, 2007), no amilanó la expansión habitacional hacia el periurbano de la macrozona urbana central del país, ni tampoco contrajo los precios de las nuevas viviendas, al menos desde 1995 en adelante (Salazar y Cox, 2014a). Sin embargo, el perfeccionamiento en un ordenamiento jurídico-subsidiario coherente con las necesidades insolutas por vivienda, ha delimitado un amplio campo de garantías en cuanto a la obtención de la casa propia, pero con precarios servicios en un contexto metropolitano donde el enfoque de lo residencial está asentado sobre los desplazamientos y ocupaciones de sus millones de habitantes. Este último lleva décadas siendo observado por distintos estudios, los que han descrito las relaciones y tensiones presentes tanto en la movilidad como en el desarrollo cotidiano de las actividades urbanas (de Mattos, 2002; Tapia, 2014).

Entonces ¿cuál ha sido el espíritu de las políticas públicas para la construcción de la casa propia? Auscultar estas acciones requiere de una revisión sobre documentos clave, que no pertenecen a la legislación en sí, sino que forman parte de los dispositivos que la organizan y sustentan en el contexto del debate articulador de la ley. El rostro humano que ha sido descrito en lo precedente, no se configura sólo desde un orquestado conjunto de acciones institucionales; descansa también, en el asiento de las intenciones que cada gobierno pretende instalar. Por ello, es imposible sostener que la faceta espacial en la producción política de viviendas sociales sea ubicua cuando, en realidad, su resultado empata con transacciones del poder que decantan en un producto final, compuesto por lo residencial y su focalización en grupos precarizados.

\section{Cuadro 2 - Principales subsidios habitacionales, periodo 1992-2014}

\begin{tabular}{|l|l|l|l|}
\hline \multicolumn{1}{|c|}{ Instrumento } & \multicolumn{1}{|c|}{ Público objetivo } & \multicolumn{1}{c|}{ Precio de vivienda } & \multicolumn{1}{c|}{ Forma de postulación } \\
\hline $\begin{array}{l}\text { Viviendas básicas } \\
\text { modalidades SERVIU, 1993 }\end{array}$ & $\begin{array}{l}\text { Familias con ingresos } \\
\text { mensuales entre 5 a 9 UF }\end{array}$ & Desde 200 hasta 400 UF & $\begin{array}{l}\text { Individual (jefes de hogar); o } \\
\text { colectiva (grupos de familias) }\end{array}$ \\
\hline $\begin{array}{l}\text { Programa de vivienda } \\
\text { nueva básica, 1995 }\end{array}$ & $\begin{array}{l}\text { Familias con ingresos } \\
\text { mensuales entre 5 a 9 UF }\end{array}$ & $\begin{array}{l}\text { Depende del SERVIU de cada } \\
\text { región }\end{array}$ & $\begin{array}{l}\text { Individual (jefes de hogar); o } \\
\text { colectiva (grupos de familias) }\end{array}$ \\
\hline $\begin{array}{l}\text { Programa de vivienda social } \\
\text { dinámica sin deuda, 2007 }\end{array}$ & $\begin{array}{l}\text { Adultos mayores o grupos } \\
\text { etareos sobre 65 años }\end{array}$ & $\begin{array}{l}\text { Depende de MINVU-SERVIU la } \\
\text { forma de aplicación del subsidio }\end{array}$ & $\begin{array}{l}\text { Individual (jefes de hogar); o } \\
\text { colectiva (grupos de familias) }\end{array}$ \\
\hline D.S. 116, 2014 & $\begin{array}{l}\text { Familias vulnerables, primer } \\
\text { quintil }\end{array}$ & $\begin{array}{l}\text { Hasta 2000 UF en todas las } \\
\text { comunas del país, exceptuando } \\
\text { aquellas que la ley indica }\end{array}$ & Individual por familia \\
\hline
\end{tabular}

Fuente: Elaboración propia en base a datos proporcionados por Minvu (2015). 


\section{Construcción de relato espacial en las políticas residenciales (1990-2014)}

El periodo posterior al término de la última dictadura militar en Chile, ha sido denominado como transición a la democracia (Richards, 1995). Sin embargo, y debido a la continuidad de políticas con impacto socio-espacial, es complejo establecer un cierre transicional. Los gobiernos retornan sobre un sistema de elecciones secretas, universales e informadas, pero ninguno de ellos ejecuta sustanciales cambios sobre el modelo económico; lo que ha sostenido los procedimientos para la asignación de recursos o el concurso para su adjudicación por parte de los grupos sociales más vulnerables, en los conocidos subsidios para la vivienda. En este sentido, la idea de un periodo de postdictadura para describir las formas políticas contemporáneas en Chile, ha sido refrendada en los últimos lustros (Mayol y Ahumada, 2015).

En este contexto, el Ministerio de Vivienda y Urbanismo - Minvu - ha organizado un posicionamiento respecto de la producción de espacio urbano y residencial, que cada gobierno ha pensado para el país, desde 1990 en adelante. Existiendo en todos ellos elementos que se repiten, se destaca que cada escrito pretende levantar un sello distintivo excepcional. Los documentos principales evacuados durante el periodo indicado, corresponden a los siguientes:

a) Política de Desarrollo Territorial (19931996). Gestionada entre los gobiernos del decenio democratacristiano de Patricio Aylwin y Eduardo Frei Ruiz-Tagle, se construye sobre la necesidad de generar equilibrios territoriales en la gestión pública del suelo urbano; las áreas metropolitanas y ciudades medias, bajo el emergente enfoque de sustentabilidad; el que aparece descrito no sólo como una declaración de necesidades ecológico-ambientales, sino que referido a la eficiencia en el uso de los recursos, equidad social en la distribución de costo-beneficio y el compromiso social con el patrimonio y las futuras generaciones (Minvu, 2012, p. 79).

Adosado a lo anterior, y como principal eje crítico, se describe la problemática en el ejercicio sin contrapesos del derecho a la propiedad, el que generaría distorsiones frente al perfil de bienes comunes y espacios públicos que son considerados como esenciales dentro de este conjunto de declaraciones. Por ello, al proponer mecanismos de compensación basados en el precio de las viviendas 0 exención de gravámenes territoriales, se configuran patrones de base para comprender que la distancia de la vivienda prioritaria para estratos vulnerables, constituye un resultado esperado por las políticas habitacionales y no una simple externalidad resultante de la articulación de instrumentos de planificación territorial que afecten distintas escalas (Hidalgo, 2007; Tapia, 2011).

Vale destacar que las reformas de este periodo, más allá del contenido y espíritu descrito, son el paso siguiente de políticas sociales iniciadas bajo el régimen militar. Ambos gobiernos citados más arriba, optaron por tomar las apuestas expansivas en materia de vivienda, de forma más sofisticada y tecnocrática, pero sin perder al mercado como articulador sobre la oferta y stock residencial para estos fines. Si al rostro humano debe 
fechársele en alguna etapa, es probable que esta sea la más adecuada.

b) Reforma Urbana (2001). Esta instancia tiene su génesis en un mandato mayor al reseñado anteriormente, cuya formación técnico-política representó la acción de distintas secretarías de estado en función de los temas propuestos.

El Consejo Nacional de la Reforma Urbana, órgano evacuado por la reforma señalada, tiene como objetivo principal acompañar a la presidencia de la nación, que en esa fecha estaba bajo la administración del socialista Ricardo Lagos Escobar, hacia "la definición de una política nacional urbana y con el diseño, formulación y coordinación de un Plan de Reforma Urbana". ${ }^{5}$ Lagos Escobar había dirigido anteriormente la secretaría de Obras Públicas, destacando el fuerte impulso a las concesiones en infraestructura entregadas a consorcios privados multinacionales, algo que tuvo continuidad durante su mandato, expandiendo este nicho de renta espacial a otras dimensiones, como la construcción de hospitales y cárceles.

Este nuevo Consejo tendría a su cargo, por lo tanto, la evacuación de productos pertinentes para la confección de políticas territoriales; coordinación interministerial e intersectorial entre los aparatos públicos adscritos al asunto espacial-residencial; además de las coordinaciones financieras para ejecutar los planes que de ello resultaren. Así, aparecen algunos elementos destacables para ilustrar la perspectiva de rostro humano que antecede a este apartado. Que el mercado sea considerado como un eficiente regulador urbano y territorial (MINVU, 2012, p. 123) es, de suyo, ejemplificador de la conducta esbozada.
Aunque la perspectiva habitacional no aparezca de forma directa en este trabajo, se proyecta longitudinalmente. La propuesta de un espacio urbano articulado en nuevos servicios, con una sólida estructura vial y donde los denominados impuestos verdes sean los que concentren el mayor aporte en bienes públicos como parques urbanos y cubiertas vegetales, busca definir una línea de base para la gestión de dispositivos de ordenamiento territorial efectivos, en cuanto al distanciamiento de los centros urbanos y los nuevos sectores habitacionales en las zonas metropolitanas. Esta condición aparece en estudios recientes acerca de sustentabilidad urbana en Santiago, principalmente, donde los episodios de crisis ambiental durante el invierno, no han decaído y sólo han ido al alza durante el último quinquenio (Schmitz, 2005; Smith y Romero, 2016).

c) Avance para una Política de Desarrollo Urbano (2009). La primera presidencia de la también socialista Michelle Bachelet destaca, entre otros aspectos, por la instalación de una Red de Protección Social institucional, desarrollando una inédita articulación subsidiaria, gestándose un nuevo horizonte del Estado neoliberal chileno.

Este sistema, de carácter intersectorial, conocido como Chile Solidario(Mideplan, 2004), gestiona y ejecuta la principal focalización de recursos fiscales hacia la mantención de las áreas precarias del desarrollo social, tanto a nivel rural como urbano, considerando como ejes particulares el acceso a la salud; ingreso a la educación escolar en todos sus niveles (Galasso, 2011); participación en subsidios para la vivienda de carácter social (Posner, 2012); y empoderamiento administrativo de los 
municipios junto al Ministerio de Planificación Nacional para cada una de las políticas que sean tributarias de esta nueva red. ${ }^{6}$ De la mano con esta estructura estatal enfocada en los sectores sociales de menor ingreso, aparece el concepto de derecho a la ciudad como espina vertebral en la producción de la citada perspectiva sobre el desarrollo urbano.

Esta referencia no es menor, especialmente si se considera que, en el anterior documento, debía ser el mercado quien regulase la producción equilibrada de lo urbano. Este caso representa, empero, el ingreso de la idea-fuerza que representa tal derecho en el debate sobre las ciudades en la actualidad. ${ }^{7}$ La responsabilidad del Estado sobre este nuevo mandato, se sintetiza en que

establecerá una "Política de Desarrollo Urbano Sustentable" basada en el "derecho a la ciudad", asegurando a todos/as los chilenos el derecho al acceso a bienes públicos de calidad, tales como: suelo urbano integrado, aire limpio; seguridad; transporte público, espacios públicos, áreas verdes y paisajes naturales protegidos; viabilidad urbana; equipamiento comunitario y acceso a servicios. Estos bienes públicos, imprescindibles para asegurar la calidad de vida urbana y la sustentabilidad a largo plazo de nuestras ciudades, no pueden depender sólo del mercado y la capacidad económica de las personas y familias para acceder a ellos. (Minvu, 2012, p. 134)

En lo anterior, no aparece siquiera mencionado el acceso a la propiedad residencial, que en los documentos precedentes estaba situado tanto las personas como en el mercado. El enfoque de este derecho a la ciudad consiste en la producción de entorno habitacional, disgregando sus áreas de acción sobre el espacio público, los bienes y servicios presentes en las ciudades chilenas. Con todo, se hace una importante mención al panorama de la localización que han tenido las viviendas de interés social, reconociendo que el precio del suelo ha generado un destino para el sueño de la casa propia de este tipo, hacia las zonas con menor motilidad respecto de ocupaciones, actividades cotidianas o de salud, entre otros (Zunino e Hidalgo, 2009; Rovira, 2009).

\section{d) Política Nacional de Desarrollo Urbano} (2014). El documento final de esta secuencia considera un epígrafe relevante, al mencionar los conceptos de ciudades sustentables y calidad de vida como parte central en el cuerpo del documento. Si la lógica anterior había oscilado entre la normalización del espacio urbano, el rol del mercado y el derecho a la ciudad, con esta nueva etapa busca consolidar las posiciones anteriores, pero también se hace cargo del oxímoron de los tiempos: justicia social. Esto acontece durante el gobierno de Sebastián Piñera, el primer gobernante de derecha política electo en 52 años, quien instala una serie reformas denominadas como estructurales, pero sin alterar esta estructura de aportes. Incluso, como lo muestra una primera tabla en este trabajo, aumentó el número de instrumentos subsidiarios para la vivienda, como es el caso del subsidio al alquiler o el de localización, que se verá más adelante.

Para ello, la política inscribe doce principios rectores para esta nueva faceta, destacándose entre ellos la equidad, en cuanto al "acceso a bienes públicos urbanos, a participar en las oportunidades de crecimiento y desarrollo"; y la integración social, considerando que las ciudades "deben ser 
lugares inclusivos, que entreguen condiciones básicas de calidad de vida a todos sus habitantes, respetando sus particularidades y su libertad de expresión" (Minvu, 2014). La relevancia de estas líneas de acción, más allá de la declaración de intenciones que el Estado manifiesta hacia el futuro, considera un campo de acción que, precisamente, se materializa sobre las formas de producción de espacio urbano.

Es interesante destacar que dichos principios, se reproducen en declaraciones más específicas dentro del citado documento. Esto, porque el componente principal sobre el cual se materializan estas líneas de acción es, precisamente, la vivienda social. Aquí el escrito es claro al refrendar que el principio de integración social debe contener nuevas situaciones de segregación urbana, y lo indica sosteniendo que

los programas de vivienda social deben considerar, especialmente, los aspectos que escapan de la iniciativa de los futuros residentes, como son la localización, los trazados del espacio público, la reserva de terrenos para equipamiento, los elementos estructurales de las viviendas y la flexibilidad para su crecimiento. (Minvu, 2014, p. 26)

Estos elementos escapan de lo que ocurre, cuando las intenciones y subsidios se convierten en un conjunto de residencias para estratos sociales vulnerables, donde el acceso a servicios mínimos sociales, como educación y salud, es precario; y cuando el uso de espacios públicos sustentables en lo ambiental y social es escaso. El expolio urbano, que era desarrollado en la década de 1970 por Kowarick (2000), y que ha tenido en Chile importantes repercusiones, no logra revertir en el inicio de esta nueva propuesta para el desarrollo urbano, la compleja tendencia anterior (Burgos et al., 2011).

El más claro ejemplo respecto al continuismo en materia habitacional, está en la localización de los conjuntos residenciales en los veinte años que han sido referidos a lo largo del presente apartado. La siguiente ilustración expone dicha tendencia, la que permite abrir la discusión hacia el rol espacial de aquel rostro humano en las áreas metropolitanas de Valparaíso y Santiago (ver Figuras 1 y 2). 
Figura 1 - Localización viviendas sociales, área metropolitana de Santiago (1992-2002; 2002-2012)

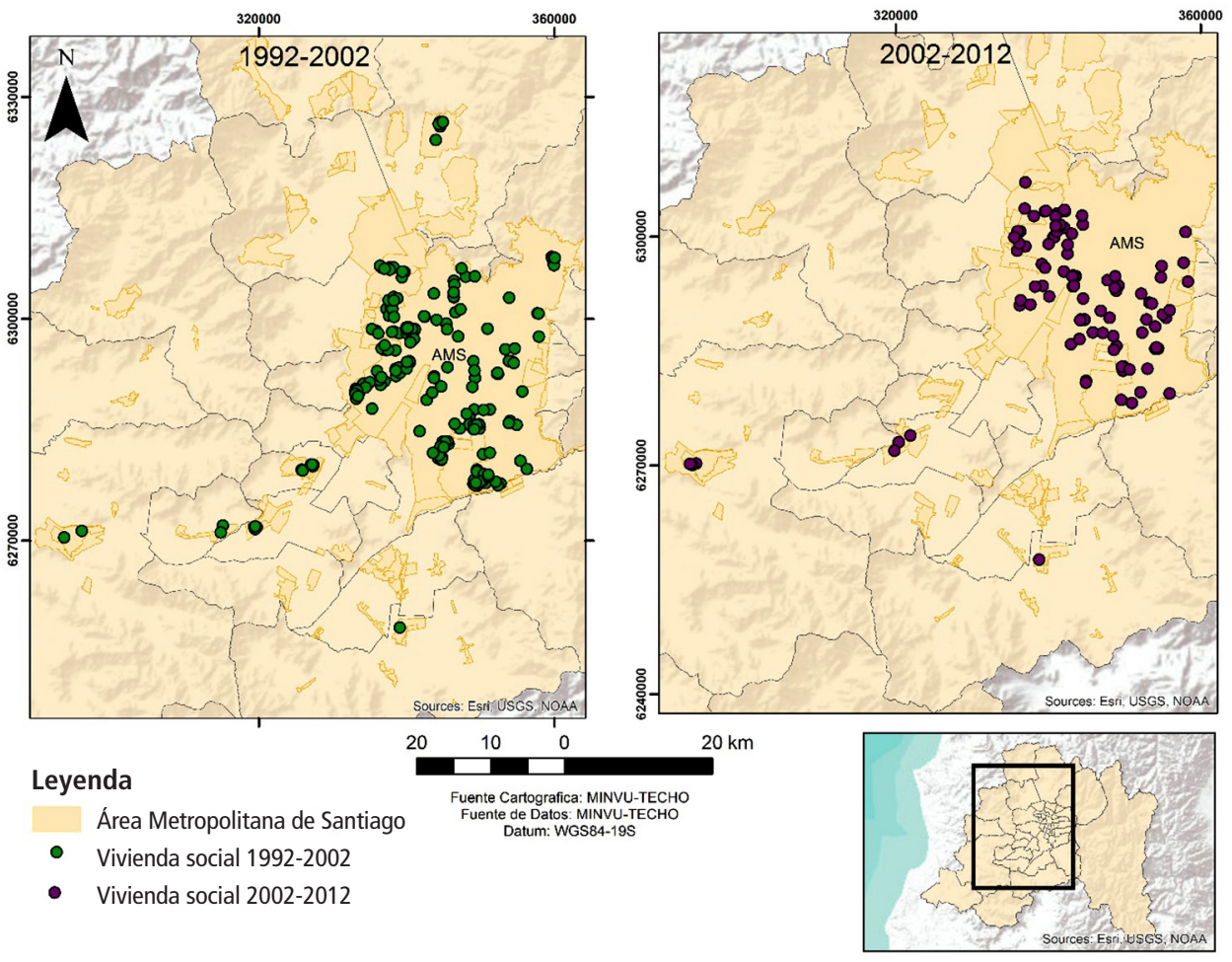

Fuente: elaboración propia en base a datos Minvu-Techo. 
Figura 2 - Localización viviendas sociales, área metropolitana de Valparaíso (1992-2002; 2002-2012)

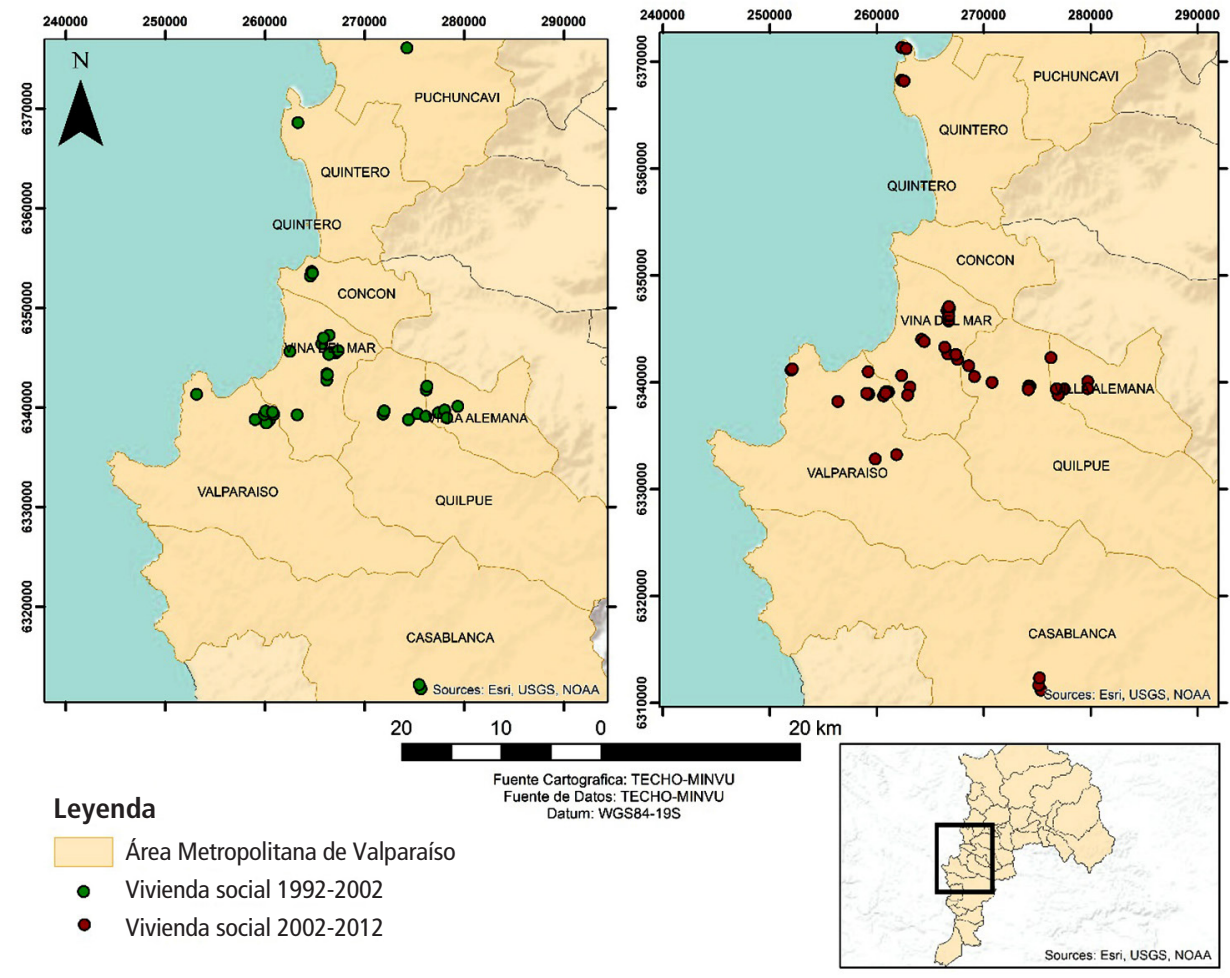

Fuente: elaboración propia en base a datos Minvu-Techo. 


\section{Un montón de ladrillos o la cara visible del neoliberalismo en el espacio urbano metropolitano chileno}

Al concretarse el retorno a la democracia en Chile, con ocasión del ascenso presidencial de Patricio Aylwin en 1990, son trazadas ciertas hojas de ruta con el fin de transparentar, primero, los reales resultados de las políticas sociales principalmente, que la dictadura cívico-militar había ejecutado, especialmente en el colofón de su periodo (1985-1980); y, desde ellos, organizar una agenda legislativa que diera cuerpo fundacional a una nueva democracia. Casi un tercio de todos los programas para la vivienda social fueron evacuados y puestos en rigor durante el gobierno del citado mandatario (ver Cuadro 1). Con ellas, el último decenio de la pasada centuria, consolida la mitad de los mismo, totalizando quince instrumentos de aportes fiscales para la vivienda.

\section{Santiago: algunos ejemplos}

Aquí emergen varios elementos, que han sido revisados en distintas publicaciones. El más importante de todos, consiste en la apuesta programática por alcanzar un millón de viviendas decepcionadas por sus propietarios para el cambio de siglo (Hidalgo, 2005). Siendo un número complejo de alcanzar, se llega a dos tercios de los comprometidos, sin dejar de lado una importante serie de externalidades que sólo se visualizan en años posteriores, como el colapso de los conjuntos residenciales de El Volcán (Portela, 2006) y Bajos de Mena en la comuna de Puente Alto.

Actualmente, el gobierno regional metropolitano de Santiago, desarrolla un plan de recuperación del sector Bajos de Mena, que albergó a los conjuntos habitacionales citados, en relación a una agenda prioritaria de cinco líneas: generar conectividad intercomunal; generar conectividad interna; nuevas áreas verdes; nuevo equipamiento; y regeneración y mejoramiento habitacional. ${ }^{8}$ Este conjunto de iniciativas empalma, de forma categórica, con los elementos descritos en las políticas de 2009 y 2014, donde aparecen dos gobiernos de signo político opuesto, como es el caso de Michelle Bachelet (2006-2010), militante de Partido Socialista de Chile; y Sebastián Piñera (20102014), quien llegó a la presidencia con el apoyo de los partidos políticos denominados como centro-derecha; $y$, además, quien firma como máxima autoridad la Política de Desarrollo Urbano de 2014.

No deja de ser relevante este último dato. La continuidad en la gestión residencial de viviendas sociales, constituye un elemento central en la perspectiva espacial del Chile contemporáneo. Además de las citadas localidades, existen otras que han sido intervenidas hacia el mejoramiento de barrios, remodelación de casas y departamentos en fachada e interiores; así como también la focalización de las redes de protección social, con el fin de aumentar la satisfacción residencial de quienes las habitan. El caso de la población Parinacota, ubicada en el extremo norte de Santiago, concentra una importante intervención de recursos fiscales (ver Figura 3). 
Figura 3 - Aglomeración y localización de viviendas sociales en las poblaciones Parinacota y Bajos de Mena, Área Metropolitana de Santiago

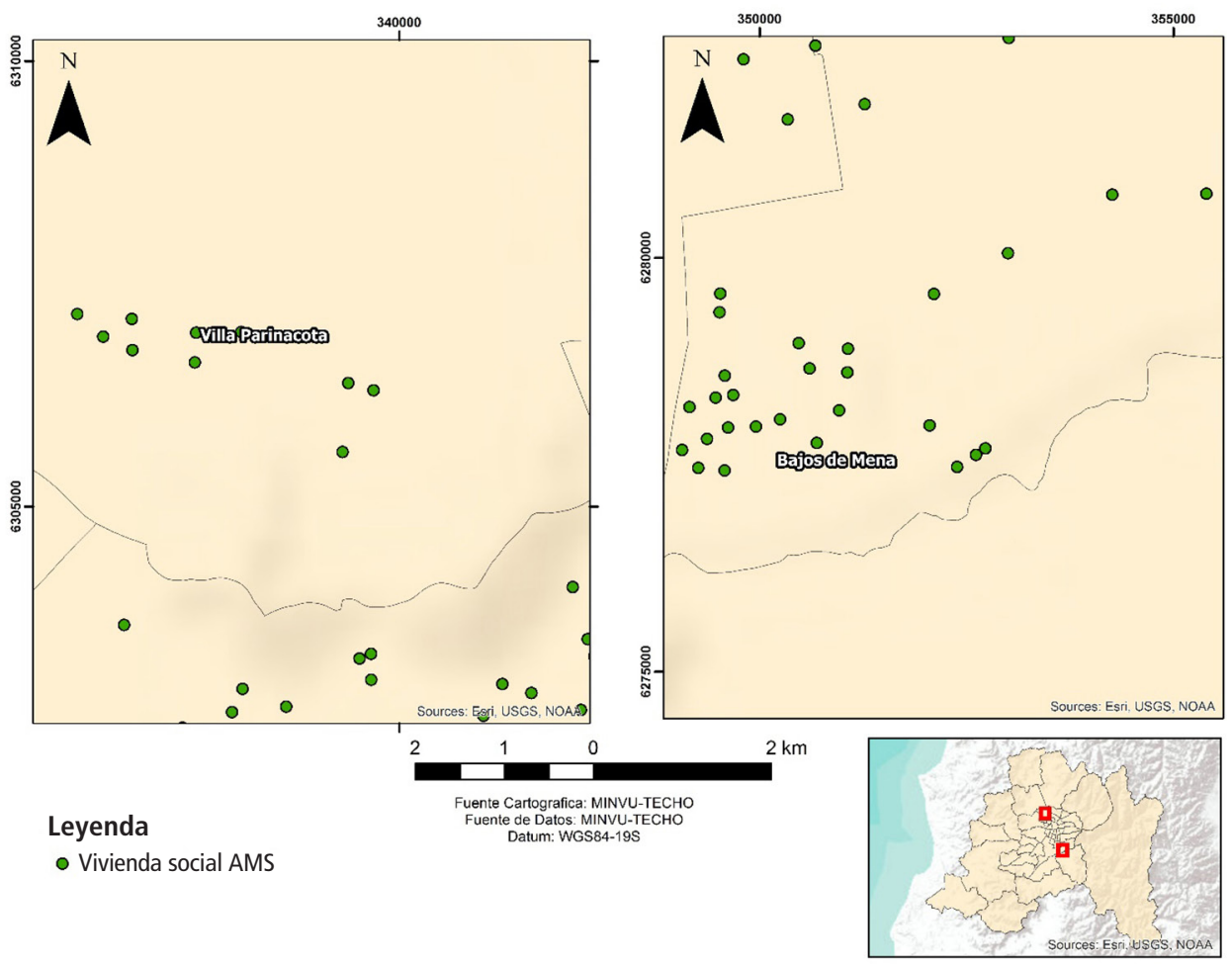

Fuente: elaboración propia en base a datos Minvu-Techo.

A partir de 2012, y sirviéndose de las redes de protección social indicadas, se inicia un intenso plan de recuperación de barrios para el conjunto residencial Parinacota, cuyo principal objetivo declara la "regeneración de barrios ubicados en sectores urbanos consolidados, cuya recuperación mejorará la calidad de vida de sus habitantes y contribuirá a su integración social y urbana" 9 ilustrando el presente accionar del Estado en materia de políticas públicas no sólo para la edificación de nuevas casas o departamentos, sino que también en la valorización de ellas en remodelación de fachadas e interiores, incluyendo espacios públicos. Siguiendo la lógica de ciudad sustentable que enmarca la Política de Desarrollo Urbano de 2014, en que no han sido pocos los recursos focalizados bajo la idea de mejoramiento tanto de las propiedades como de su entorno (Arévalo, 2004). Este caso no es aislado, en absoluto, frente a otros escenarios en que el Estado se manifiesta de forma 
oscilante en un periodo de tiempo, donde inicialmente entrega las viviendas de carácter social; para luego retornar en otra época al modo del conjunto habitacional Parinacota. La población El Castillo, en la comuna de La Pintana, refleja esta situación expectaticia, donde la espera por el retorno de lo público no es, por lo general, uniforme u homogénea (Alvarez y Cavieres, 2016).

\section{Valparaíso: otros casos}

Por otro lado, en el área metropolitana de Valparaíso, la pendular acción fiscal en el espacio urbano, se refleja en casos similares a los anteriormente indicados, pero con particularidades conflictivas entre lo natural y lo patrimonial.

La declaración patrimonial de 2003, por parte de Unesco, que sólo cubre al casco histórico de la ciudad-puerto; no se condice en absoluto con lo que acontece hacia los cerros que envuelven la bahía de Valparaíso. A partir de una serie de incendios ocurridos entre 2013 y 2014, en la zona de La Pólvora y los cerros Mariposa y Las Cañas, entre otros, es develada la precariedad en el acceso a servicios de alcantarillado y electricidad regulada en aquellos sectores que, siendo habitacionales, carecían de planificación alguna. Esta crítica situación obliga al Minvu a tramitar una resolución que otorga, sin concurso alguno, aportes para la construcción de nuevas casas y departamentos; y así desmantelar posibles eventos de similares características en otras localidades del área metropolitana de Valparaíso, como es el caso de las comunas de Viña del Mar y Concón. El Cuadro 3 indica los aportes que reciben, en 2015, grupos sociales en copropiedad, bajo el subsidio para la construcción de condominios sociales en el marco del Programa de Protección al Patrimonio Familiar.

Cuadro 3 - Grupos beneficiados REX n 2016, Ministerio de Vivienda y Urbanismo-Seremi Valparaíso, 2015

\begin{tabular}{|l|l|c|}
\hline \multicolumn{1}{|c|}{ Comuna } & \multicolumn{1}{|c|}{ Nombre del grupo } & $\begin{array}{c}\text { Total, aporte fiscal } \\
\text { (millones de pesos) }\end{array}$ \\
\hline Viña del Mar & $\begin{array}{l}\text { Comité de Adelanto y Seguridad Ciudadana } \\
\text { Polígono 1 La Concepción }\end{array}$ & $896.869 .792^{10}$ \\
\hline Concón & CCSS Horizontes del Mar-RPC & 592.194 .854 \\
\hline
\end{tabular}

Fuente: elaboración propia en base a REX N 2016 Minvu-Seremi. 
La presencia de estos aportes, refrenda sólo una acción de la gestión subsidiaria residencial en el Estado neoliberal chileno. El mencionado programa patrimonial indica, además del financiamiento para la construcción de condominios sociales, la opción de financiar equipamiento comunitario o entorno; mejoramiento, refacción y remodelación de viviendas ya en patrimonio individual; optimización de los sistemas de calefacción y aislación para regiones del sur chileno; y obras de ampliación por individualización espacial de viviendas -cocinas, dormitorios o baños - (Minvu, 2011). Este programa ha tenido una continuidad desde 2007 a la actualidad, representando un conjunto de acciones a mediano plazo, que ha sido solventada por gobiernos de signo político antagónico, pero insertos en los ejes longitudinales que promueven las políticas de desarrollo urbano que se presentan en la sección anterior. En suma, es relevante señalar, que, entre dos gobiernos de distinto signo político, no se aprecian importantes diferencias entre los modelos de acceso a estos beneficios, sino que acusan una expansión hacia nuevos nichos de mercado, como la edificación de condominios sociales y la mantención del plusvalor de la vivienda, considerando que la propiedad habitacional constituye, en el caso de los grupos sociales beneficiados por estos aportes, la única fuente patrimonial efectiva hacia el futuro.

\section{Ideas finales}

Los resultados obtenidos a la fecha evidencian dos tendencias. La primera de ellas está en que el neoliberalismo ostenta dentro de sus características, una importante faceta espacial que materializa los flujos de acumulación y renta en nichos urbanos de negocios y extracción de ganancias, principalmente (Lefebvre, 1976). En segundo término, el caso chileno evidencia particularidades en la sostenida expansión de negocios residenciales, lo que podría suponer que la subsistencia del modelo de acumulación neoliberal, en el sentido del espacio, opera como agencia en la urbanización extendida de las áreas metropolitanas de Valparaíso y Santiago. En este caso, la vivienda social cumple un rol fundamental toda vez que ella incorpora a grupos sociales vulnerables a los circuitos del mercado laboral y el consumo, al convertirlos en propietarios de un bien raíz; $y$, en consecuencia, en sujetos de crédito (de Mattos, 2002).

Las unidades espaciales consideradas en esta revisión, conforman las áreas metropolitanas de Valparaíso y Santiago, donde se concentra el mayor volumen de población en Chile; y, al mismo tiempo, donde la aglomeración de servicios urbanos y el consumo de bienes tiene un tamaño superior al resto del país. En este sentido, la producción residencial, las operaciones urbanas y la expansión de los subsidios focalizados en la demanda por vivienda social, han redibujado la trama de dichas metrópolis (Hidalgo et al., 2014), estableciendo variados nichos de acumulación y renta urbanas devengadas de las acciones que el Estado, en tanto agente esencial en la producción neoliberal del espacio, acomete en la organización territorial de lo urbano, para cubrir el requerimiento insoluto de la propiedad habitacional para grupos sociales vulnerables (Lencioni, 2011). 
A pesar de que el neoliberalismo en las políticas urbanas y de vivienda social ha asumido un nuevo rostro humano, reflejado en el interés por la equidad, la mixtura social y la sustentabilidad - algo que se refleja en los planes y programas revisados - la retórica ideológica se aparta de las prácticas reales de producción de espacio urbano que siguen ocasionando una mayor perifización de las clases populares ahora expulsadas a las periferias de lo que Hidalgo et al. (2014) denominan como Macrozona Urbana Central y sobre todo la disolución de la ciudad en un magma informe de áreas hibridas en las que lo urbano degrada lo rural, y lo rural lo urbano (Lefebvre, 2014).

Se podría concluir que el neoliberalismo en las políticas urbanas y de vivienda social en Chile ha redefinido no solamente el discurso de la planificación urbana y regional, sino que ha contribuido a facilitar la reproducción del capitalismo más allá de la minería y la agroindustria; la producción neoliberal del espacio urbano se convertido como lo señalaba Lefebvre (1976) en ámbito neurálgico para la acumulación de capital. Lo anterior ha ocurrido mediante la ampliación y mutación de lo que Harvey (2012) denomina "nexo Estado-Finanzas" y lo que Aalbers (2012) Ilama "complejo inmobiliariofinanciero". La trama ideológica que sustenta ese nexo y ese complejo hace menos evidente esa ampliación y mutación, por lo que interpretar ese proceso es una de las tareas pendientes de la economía política urbana de carácter crítico.

\section{Rodrigo Hidalgo Dattwyler}

Pontificia Universidad Católica de Chile, Instituto de Geografía. Santiago, Región Metropolitana, Chile.

rhidalgd@uc.cl

\section{Voltaire Christian Alvarado Peterson}

Pontificia Universidad Católica de Chile, Instituto de Geografía. Santiago, Región Metropolitana, Chile.

vcalvarado@uc.cl

\section{Daniel Santana Rivas}

Pontificia Universidad Católica de Chile, Instituto de Geografía. Santiago, Región Metropolitana, Chile.

Idsantana@uc.cl 


\section{Notas}

(*) Este artículo expone los resultados de investigación acumulados en FONDECYT 1150360 "La política de Vivienda Social en las áreas metropolitanas de Santiago y Valparaíso: entre la desigualdad y sostenibilidad del desarrollo urbano (1992-2014)".

(1) Estos elementos son desarrollados por Pilar Vergara a lo largo del citado trabajo, y se presentan aquí de forma sintética (1984).

(2) Ante la imposibilidad de tipificar de forma homogénea el ansiado derecho a la vivienda, se evita proponer el argumento bajo tal categoría; esto, toda vez que en Chile al menos, el acceso a la propiedad residencial no se ejerce como derecho, para ningún grupo social.

(3) Los valores están expresados en unidades de fomento (UF) en la citada norma. La UF es unidad de cuenta que se utiliza para otorgar plusvalor a las hipotecas y bienes raíces en general; que, además, se reajusta diariamente dependiendo del comportamiento del indicador de precios al consumidor (IPC). El monto de una UF para el último día de agosto de 2016, corresponde a 26.209 pesos chilenos, equivalente a 41 dólares americanos.

(4) Los quintiles corresponden a la estratificación por ingreso per cápita, realizada a través de los instrumentos para la medición de la pobreza contenidos en Casen. El primer quintil concentra a aquellas familias cuyo ingreso mensual por integrante, no supera los 53.184 pesos chilenos, equivalente a 80,24 dólares americanos. El detalle de la encuesta puede consultarse en la web http://www.encuestacasen.cl (consultada en septiembre de 2016).

(5) Artículo $1^{\circ}$, Decreto $n^{\circ} 187$ "Crea Consejo Nacional para la Reforma Urbana", Ministerio de Vivienda y Urbanismo. 3 de noviembre de 2001.

(6) El municipio corresponde a la mínima unidad espacial en la administración territorial del Estado. La anteceden la provincia, que se refieren a un conjunto de comunas; y la región, que reúne a las provincias en áreas de mayor escala.

(7) Con la revisita permanente sobre la obra de Henri Lefebvre, se presenta un interesante espacio contemporáneo para la discusión acerca de este derecho a la ciudad que, si bien corresponde a la obra del filósofo francés su puesta en marcha, ha rebotado con mucha fuerza sobre instancias internacionales como Hábitat-ONU, y también en el debate académico.

(8) El detalle de todas las acciones que ejecuta al Intendencia de Santiago, quien dirige el gobierno regional, están contenidas en una página web dinámica y en permanente actualización hacia la comunidad. Está disponible en la dirección https:// http://www.planintegralbajosdemena.cl/ (Consultada en agosto de 2016).

(9) Artículo $1^{\circ}$, Resolución Exenta $n^{\circ} 3680 / 2012$. Servicio de Vivienda y Urbanismo Metropolitano "Aprueba Convenio con Municipalidad de Quilicura. Programa de Recuperación de Barrios".

(10) Los valores están expresados en unidades de fomento (UF) en la citada norma. La UF es unidad de cuenta que se utiliza para otorgar plusvalor a las hipotecas y bienes raíces en general; que, además, se reajusta diariamente dependiendo del comportamiento del indicador de precios al consumidor (IPC). El monto de una UF para el último día de agosto de 2016, corresponde a \$26.209 pesos chilenos, equivalente a \$41 dólares americanos. 


\section{Referencias}

AALBERS, M. (2012). "European Mortgage Markets Before and After the Financial Crisis". In: M. AALBERS (ed.). Subprime cities. The political economy of mortgage markets. Oxford, Blackwell.

ÁlVAREZ, A. y CAVIERES, H. (2016). El Castillo: territorio, sociedad y subjectividades a la espera. Eure, v. 42 , n. 125 , pp. $155-174$.

ARÉVALO, F. (2004). Rehabilitación de la población Parinacota-Quilicura. Memoria de título para optar al título profesional de Arquitecto. Santiago, Universidad de Chile.

ATRIA, F. (2013). Neoliberalismo con rostro humano (veinte años después). Santiago de Chile, Editoria Catalonia.

BAEHR, J. y MEYER-KRIESTEN, K. (2007). Santiago de Chile: a fragmented city? A factorial analysis of the urban structure in 2002 in comparison with 1970. Erdkunde, v. 61, n. 3, pp. 258-276.

BLANCO, A.; FRETES, V. y MUÑOZ, A. (2014). Se busca vivienda en alquiler. Opciones de política en América Latina y el Caribe. Nueva York, Monografía del BID-Banco Interamericano de Desarrollo.

BORÓN, A.; GAMBINA, J. C. y MINSBURG, N. (Eds.) (2004). Tiempos violentos. Neoliberalismo, globalización y desigualdad en América Latina. Buenos Aires, Consejo Latinoamericano de Ciencias Sociales.

BORSDORF, A. e HIDALGO, R. (2008). New dimensions of social exclusion in Latin America: from gated communities to gated cities, the case of Santiago de Chile. Land Use Policy, v. 25, n. 2, pp. 153-160.

BURGOS, S.; JORGE, R.; MONTAÑO, R. y ATRIA, J. (2011). Tipologías residenciales en comunidades chilenas en condiciones de precariedad habitacional. Revista Panamericana de Salud Pública, v. 29, n. 1, pp. 32-40.

CALVACANTI, D. y CRUZ, B. (2014). A produção do programa Minha Casa Minha Vida na região metropolitana da Baixada Santista: reafirmação da configuração metropolitana e exclusão socioterritorial. Pensamento e Realidade, v. 29, n. 3, pp. 116-134.

CARLOS, A. F. (2015). “EI “derecho a la ciudad” como pensamiento-acción”. In: DE MATTOS, C. y LINK, F. (eds.). Lefebvre revisitado: capitalismo, vida cotidiana y derecho a la ciudad. Santiago de Chile, Ril Editores-Colección Estudios Urbanos UC.

COQ-HUELVA, D. (2013). Urbanisation and financialisation in the context of a rescaling state: the case of Spain. Antipode, v. 45, n. 5, pp. 1213-1231.

CRUMP, J.; NEWMAN, K.; BELSKY, E.; ASHTON, P.; KAPLAN, D.; HAMMEL, D. y WYLY, E. (2008). Cities destroyed (again) for cash: forum on the US foreclosure crisis. Urban Geography, v. 29, n. 8, pp. 745-784.

DE MATTOS, C. (2002). Mercado metropolitano de trabajo y desigualdades sociales en el Gran Santiago. ¿Una ciudad dual? Eure, v. 28, n. 85, pp. 51-70.

FOUCAULT, M. (2007). El nacimiento de la biopolítica. Curso en el Collège de France (1978-1979). Buenos Aires, Fondo de Cultura Económica.

GALASSO, E. (2011). Alleviating extreme poverty in Chile: the short term effects of Chile Solidario. Estudios de Economía, v. 38, n. 1, pp. 101-127. 
GÁRATE, M. (2012). La revolución capitalista de Chile (1973-2003). Santiago de Chile, Ediciones Universidad Alberto Hurtado.

HARVEY, D. (2012). El enigma del capital. Madrid, Akal.

HEROD, A. (1997). From a geography of labor to a labor geography: labor's spatial fix and the geography of capitalism. Antipode, v. 29, n. 1, pp. 1-31.

HIDALGO, R. (2005). La vivienda social en Chile y la construcción del espacio urbano en el Santiago del siglo XX. Santiago de Chile, Centro de Investigaciones Diego Barros Arana-Serie GEOlibros Instituto de Geografía de la Pontificia Universidad Católica de Chile.

(2007). ¿Se acabó el suelo en la gran ciudad? Las nuevas periferias metropolitanas de la vivienda social en Santiago de Chile. Eure, v. 33, n. 98, pp. 57-75.

HIDALGO, R. y BORSDORF, A. (2005). Puerto abierto ¿ciudad cerrada? transformaciones socioespaciales en la estructura urbana del área metropolitana de Valparaíso. Revista Geográfica de Valparaíso, n. 36, pp. 189-206.

HIDALGO, R.; ARENAS, F.; PAULSEN, A.; SANTANA, D. y LINK, F. (2016b). "Discursos sobre justicia y desigualdad en las políticas de vivienda social en Chile". In: ORELLANA, A.; LINK, F. y NOYOLA, J. (eds.). Urbanización planetaria y la reconstrucción de la ciudad. Santiago de Chile, Ril EditoresColección Estudios Urbanos UC.

HIDALGO, R.; ARENAS, F.; SÁNCHEZ, R. y VOLKER, P. (2014). "La macrozona urbana central chilena: formas de crecimiento, vulnerabilidad y sustentabilidad". In: WILLIAMS, J.; HIDALGO, R.; BRAND, P. y PÉREZ, L. (eds.). Metropolizaciones Colombia-Chile. Experiencias de Bogotá, Medellín, Santiago y Concepción. Medellín, Facultad de Arquitectura, Universidad Nacional de Colombia.

HIDALGO, R.; SANTANA, D. y ALVARADO, V. (2016a). “Mitos, ideologías y utopías neoliberales de la producción del espacio: hacia una agenda de investigación alternativa". In: HIDALGO, R. et al. (orgs.). Las costas del neoliberalismo. Naturaleza, urbanización y producción inmobiliaria: experiencias en Chile y Argentina. Santiago de Chile, PUC-Geolibros.

HOJMAN, D. (1995) (ed.). Neoliberalism with human face? The politics ans economics of the chilean model. Liverpool, Institute of Latin American Studies-University of Liverpool.

KOWARICK, L. (2000). Escritos Urbanos. São Paulo, Editora 34.

KRUGMAN, P. (1992). Geografía y comercio. Barcelona, Barcelona Antoni Bosch.

LEFEBVRE, H. (1976). Espacio y Política. El derecho a la ciudad II. Barcelona, RIGSA.

(2014). El pensamiento marxista y la ciudad. México, Coyoacán.

LENCIONI, S. (2011). "Referencias analíticas para a discussão da metamorfose metropolitana". In: LENCIONI, S.; VIDAL-KOPPMANN, S.; HIDALGO, R. e PEREIRA, P. (orgs.). Transformações sócioterritoriais nas metrópoles de Buenos Aires, São Paulo e Santiago. São Paulo, FAUUSP-Serie GEOlibros.

MAYOL, A. y AHUMADA, J. (2015). Economía política del fracaso : la falsa modernización del modelo neoliberal. Santiago de Chile, El Desconcierto.

MINISTERIO DE PLANIFICACIÓN Y COOPERACIÓN-CHILE (2004). Conceptos Fundamentales Sistema de Protección Social Chile Solidario. Ministerio de Planificación y Cooperación-Chile. Disponible en: http://www.ministeriodesarrollosocial.gob.cl/admin/docdescargas/centrodoc/centrodoc_170. pdf. Consultado en: septiembre de 2016). 
MINISTERIO DE VIVIENDA Y URBANISMO-CHILE (2011). Programa de Protección del Patrimonio Familiar. Informe Final. Santiago de Chile, Minvu.

(2012). Hacia una nueva Política Urbana para Chile. Antecedentes Históricos. Santiago de Chile, Minvu-PNUD.

(2014). Política Nacional de Desarrollo Urbano. Ciudades Sustentables y Calidad de Vida. Santiago de Chile, Minvu-PNUD.

(2015). Informe final Consejo Nacional de Desarrollo Urbano. Propuestas para una política de suelo para la integración social urbana. Santiago de Chile, Minvu.

MOULIAN, T. (2002). Chile actual. Anatomía de un mito. Santiago de Chile, LOM Ediciones.

NIEDT, C. y MARTIN, I. (2013). Who Are the Foreclosed? A Statistical Portrait of America in Crisis. Housing Policy Debate, v. 23, n. 1, pp. 159-176.

OXHORN, P. (1999). Recent research on Chile: the challenge of understanding "success". Latin American Research Review, v. 34, n. 1, pp. 255-271.

PIERSON, P. (1995). Dismantling the welfare state?: Reagan, Thatcher, and the politics of retrenchment. Cambridge, Cambridge University Press.

PORTELA, D. (2006). El Volcán: etnografía de un ghetto en Santiago. Identidad, capital social y control cultural en la vivienda social. Tesis para optar al grado de Licenciado en Antropología Social. Santiago, Universidad Academia de Humanismo Cristiano.

POSNER, P. (2012). Targeted Assistance and social capital: housing policy in Chile's neoliberal democracy. International Journal of Urban and Regional Research, v. 1, n. 36, pp. 49-70.

POZO, H. y VERGARA, P. (1990). Políticas sociales y extrema pobreza en Chile. Proposiciones-Ediciones SUR, v. 18, pp. 159-178.

RICHARDS, B. (1995). Poverty and housing in Chile: the development of a neo-liberal welfare state. Habitat International, v. 4, n. 19, pp. 515-527.

RODRIGUEZ, A. y SUGRANYES, A. (2004). El problema de vivienda de los “con techo". Eure, v. 30, n. 91, pp. 53-65.

ROVIRA, A. (2009). "La construcción de una metrópoli regional: el caso de Puerto Montt, centro urbano intermedio del sur de Chile”. In: HIDALGO, R.; DE MATTOS, C. y ARENAS, F. (eds.). Chile: del país urbano al país metropolitano. Santiago de Chile, Serie GEOlibros-Eure Libros.

SABATINI, F. y BRAIN, I. (2008). La segregación, los guetos y la integración social urbana: mitos y claves. Eure, v. 34, n. 103, pp. 5-26.

SABATINI, F. y SALCEDO, R. (2007). Gated communities and the poor in Santiago, Chile: Functional and symbolic integration in a context of aggressive capitalist colonization of lower-class areas. Housing Policy Debate, v. 3, n. 18, pp. 577-606.

SALAZAR, A. y COX, T. (2014a). Accesibilidad y valor de suelo como criterios para una localización racional de vivienda social rural en las comunas de San Bernardo y Calera de Tango. Invi, v. 29, n. 80 , pp. 53-81.

SALAZAR, A.; UGARTE, C. y OSSES, P. (2014b). Social exclusion associated with transport and its relation to the distribution of population density in the Melipilla Province, Santiago Metropolitan Region of Chile. Revista de Geografia Norte Grande, n. 59, pp. 145-164. 
SCHMITZ, R. (2005). Modelling of air pollution dispersion in Santiago de Chile. Atmospheric Environment, v. 11, n. 39 , pp. 2035-2047.

SMITH, P. y ROMERO, H. (2016). Factores explicativos de la distribución espacial de la temperatura del aire de verano en Santiago de Chile. Revista de Geografía Norte Grande, n. 62, pp. 45-62.

STIGLITZ, J. (2014). El precio de la desigualdad. Madrid, Punto de Lectura.

SWYNGEDOUW, E. (2011). i La naturaleza no existe! La sostenibilidad como síntoma de una planificación despolitizada. Revista Urban (Nueva Serie), v. 1, pp. 41-66.

TAPIA, R. (2011). Vivienda social en Santiago de Chile. Analisis de su comportamiento locacional, período 1980-2002. Invi, v. 26, n. 73, pp. 105-131.

(2014). Evolución del patrón espacial del emplazamiento de viviendas sociales en el Gran Santiago, Chile. 1980-2010. Revista Geografica Venezolana, v. 2, n. 55, pp. 255-274.

VALDIVIA, V.; ÁLVAREZ, R. y PINTO, J. (2006-2008). Su revolución contra nuestra revolución. Tomos I y II. Santiago de Chile, LOM.

VERGARA, P. (1984). Auge y caída del neoliberalismo en Chile. Un estudio sobre la evolución ideológica del régimen militar. Santiago de Chile, Documento de trabajo-Programa Flacso.

WORLD BANK (2015). The estate of social safety nets 2015. Washington D. C., International Bank for Reconstruction and Development/World Bank.

ZUNINO, H. e HIDALGO, R. (2009). Spatial and socioeconomic effects of social housing policies implemented in neoliberal Chile: the case of Valparaiso. Urban Geography, v. 30, n. 5, pp. 514-542.

Texto recebido em 28/out/2016 Texto aprovado em 17/maio/2017 
